\title{
BMP4 Mediates Apoptotic Cell Death in the Developing Chick Eye
}

\author{
Françoise Trousse, Pilar Esteve, and Paola Bovolenta \\ Departamento de Neurobiología del Desarollo, Instituto Cajal, Consejo Superior de Investigaciones Cientificas, Madrid \\ 28002, Spain
}

The bone morphogenetic protein (BMP) expression in vertebrates suggests a reiterative function of these molecules during eye development. However, genetic analysis in mice has provided only partial information. Using the chick embryo as a model system, we have analyzed possible additional functions of BMP4 during optic cup formation. Here we describe the expression pattern of Bmp4 and Bmp7 and we show that, in contrast to the mouse, the prospective lens placode ectoderm expresses high levels of Bmp4 but no Bmp7. After optic vesicle invagination, $B m p 4$ is expressed in the prospective dorsal neural retina, where BmprlA, Bmprll, and Smad1, components of the BMP4 signal transduction pathway, are also expressed. In toto terminal deoxynucleotidyl transferase-mediated biotinylated UTP nick end-labeling analysis shows that the dorsal optic cup is the site of a spatiotemporally restricted apoptosis, which parallels the expression not only of Bmp4 but also of Msx1 and Msx2, genes implicated in BMP4-mediated apoptosis. The use of optic vesicle cultures as well as in ovo local addition of BMP4 and its antagonist Noggin proves that the local activity of BMP4 is responsible for programmed cell death in the dorsal optic cup. In addition, we show that Noggin is able to reduce the rate of cell proliferation in the dorsal part of the optic cup whereas BMP4 increases the number of BrdU-positive cells in retina cultures. These results provide evidence that BMP4 contributes to eye development by promoting cell proliferation and programmed cell death.

Key words: apoptosis; Bmp7; BMP receptors; neural retina; noggin; proliferation
Eye formation in vertebrates requires a series of morphogenetic events associated with changes in cell shape, an increase in the rate of cell proliferation, and the occurrence of discrete and localized cell death (Glücksmann, 1951; Coulombre, 1965; Silver and Hughes, 1973; Cuadros and Ríos, 1988; Martín-Partido et al., 1988; Saha et al., 1992; Laemle et al., 1999). These processes are sustained by complex molecular interactions that involve members of different protein families, including bone morphogenetic proteins (BMPs).

BMPs are a large subclass of the transforming growth factor- $\beta$ superfamily of soluble proteins. Originally characterized for their osteogenetic activity (Urist et al., 1979; Wozney et al., 1988), BMPs are expressed throughout embryogenesis and play pivotal roles in processes like mesoderm and neural plate induction or dorsoventral patterning of the neural tube. In addition to these long-range activities, BMPs are involved in the proliferation and differentiation of many different tissues and organs (Hogan, 1996; Mehler et al., 1997). The activity of BMPs has been associated

Received Sept. 1, 2000; revised Nov. 6, 2000; accepted Nov. 14, 2000.

This study was supported by Spanish Dirección General de Enseñanza Grant PM97-0019 and the European Communities Grant BIO4-CT98-0399 to P.B. The Retina France Association and the Spanish Ministerio de Educación y Cultura have supported the postdoctoral work of F.T. P.E. is supported by the Comunidad Autónoma de Madrid Postdoctoral Fellowship 02-0294-1997. We are grateful to the Genetic Institute for the gift of rBMP4 protein, to Creative BioMolecules for rBMP7 protein and 1B12 blocking antibody, and to Dr. R. Harland for Noggin. Antiserum against the $\delta$-crystallin protein was a gift of Dr. J. Piatigorsky. Many of the probes for in situ hybridization were kindly provided by Drs. P. Brickell, B. Houston, R. Merino, J. Hurle, L. Niswander, and P. ten Dijke. We are indebted to Drs. A. Garda and S. Martinez for teaching bead implantation, to Dr. M. L. Cotrina for comments and expert advice on the TUNEL assay, and to Drs. J. M. Devaud and J. R. Martínez-Morales for their expert assistance with the image analysis software and statistical analysis, respectively. Drs. J. Hurle and E. Martí provided helpful insights into this manuscript.

Correspondence should be addressed to Dr. Paola Bovolenta, Instituto Cajal, Consejo Superior de Investigaciones Cientificas, Doctor Arce 37, Madrid 28002, Spain. E-mail: bovolenta@cajal.csic.es.

Copyright (c) 2001 Society for Neuroscience $0270-6474 / 01 / 211292-10 \$ 15.00 / 0$ also with developmentally regulated programmed cell death (PCD) (Furuta et al., 1997; Coucouvanis and Martin, 1999). In particular, BMP4 mediates PCD in the prospective neural crest cells before their migration from rhombomeres 3 and 5 (Graham et al., 1994) and is responsible for the apoptosis that shapes the interdigital space of the developing limbs in birds (Gañan et al., 1996; Zou and Niswander, 1996; Macias et al., 1997).

In mice, Bmp 4 and $B m p 7$ are expressed early in the developing eye, localized to the dorsal aspect of the neural retina and to the prospective pigment epithelium, respectively. Bmp7 and low levels of Bmp4 are also found in the prospective lens placode ectoderm (Lyons et al., 1995; Dudley and Robertson, 1997; Furuta and Hogan, 1998; Wawersik et al., 1999). Analysis of different Bmp7-null mice indicates that BMP7 is required for the early steps of lens induction and for proper retinal differentiation (Dudley et al., 1995; Luo et al., 1995; Wawersik et al., 1999). A complete analysis of BMP4 function via the study of Bmp4-null homozygous mice is impaired by the high embryo lethality caused by gastrulation defects (Winnier et al., 1995). However, homozygous mutant embryos that reach midgestation show an alteration in lens formation (Furuta and Hogan, 1998). Using the chick embryo as a model system, we addressed whether BMP4 has additional roles during eye morphogenesis.

Here we have analyzed the expression pattern of Bmp 4 and $B m p 7$ at early stages of embryo development. We show that Bmp4 is first detectable in the optic cup when the main inductive events necessary for eye initiation are accomplished and retina differentiation has yet to begin (Prada et al., 1991; Saha et al., 1992). We further demonstrate that the dorsal expression domain of Bmp4 colocalizes with a region of prominent and spatiotemporal-restricted PCD. Using dissociated and organotypic cultures as well as in ovo local addition of BMP4 and its antagonist Noggin, we provide evidence that BMP4 is 
responsible for apoptotic cell death and proliferation in the dorsal portion of the chick optic cup.

\section{MATERIALS AND METHODS}

Embryos. Fertilized chick eggs (White Leghorn) were incubated at $38^{\circ} \mathrm{C}$ and staged according to the method of Hamburger and Hamilton $(\mathrm{HH})$ (1951). Mouse embryos were collected from timed pregnant BALB/c mice. The day of vaginal plug appearance was considered embryonic day 0.5 (E0.5).

In situ hybridization. Whole-mount in situ hybridizations were performed as described (Bovolenta et al., 1998) using digoxigenin-labeled sense and antisense riboprobes. Hybridizations were performed at $65^{\circ} \mathrm{C}$ in $50 \%$ formamide (Fluka, Buchs, Switzerland). Posthybridization washes were performed at the same temperature and in the same buffer. After hybridization, embryos were dehydrated, embedded in Fibrowax (DBH Laboratories, Dorset, United Kingdom), and sectioned at $15 \mu \mathrm{m}$ in a microtome. The Bmp4, Bmp7, BmprIA, BmprIB, and BmprII chick probes have been described previously (Francis et al., 1994; Houston et al., 1994; ten Dijke et al., 1994; Kawakami et al., 1996; Zou et al., 1997). Probes to the chick Smad1, Msx1, Msx2, and Noggin were the kind gift of Drs. R. Merino and J. Hurle (Universidad de Cantabria, Santander, Spain).

Reverse transcription-PCR analysis. Poly $\left(\mathrm{A}^{+}\right)$RNA was prepared from HH17 chick prospective neural retina (NR) and pigmented epithelium (PE) using the Quick-prep-Micro mRNA Purification kit (Amersham Life Science). Reverse transcription (RT) was performed by random priming with the First-Strand-cDNA Synthesis kit (Amersham Life Science) following the manufacturer's instructions. Reactions to amplify fragments of the chick BmprIA, BmprIB, BmprII, Noggin, and glyceraldehy-3-phosphate dehydrogenase $(G A P D H)$ were performed using the following primer pairs: for BmprIA, a $441 \mathrm{bp}$ amplicon, the forward primer is $5^{\prime}$-CAGCTGGTTCMGAGAAACAG-3', and the reverse primer is 5'-CTTTCATCAAGGACCTCTGG-3'; for BmprIB, a 508 bp amplicon, the forward primer is $5^{\prime}$-CAGCTGGTTCMGAGAAACAG$3^{\prime}$, and the reverse primer is 5'-CCAAAGGATGAGTCCAAAGC-3'; for BmprII, a 507 bp amplicon, the forward primer is $5^{\prime}$ CGTTACCATGAATGGAGTGG-3', and the reverse primer is $5^{\prime}$-CTTGATCTTCTCTCCTGAGC-3'; for Noggin, a 672 bp amplicon, the forward primer is $5^{\prime}$-ATGGATCATTCCCAGTGCCTTGT-3', and the reverse primer is 5'-CTAGCAGGAGCACTTGCACTC-3'; and for $G A P D H$, a 158 bp amplicon, the forward primer is $5^{\prime}$ CCCGAATTCTGGGCACGCCATCACTATCTTCC-3', and the reverse primer is $5^{\prime}$-CCCGGATCCAGCTGAGATGATAACACGCTTAGC- $3^{\prime}$. Amplification conditions were the following: 30 cycles $\left(95^{\circ} \mathrm{C}\right.$, $\left.30 \mathrm{sec} ; 59^{\circ} \mathrm{C}, 30 \mathrm{sec} ; 72^{\circ} \mathrm{C}, 30 \mathrm{sec}\right)$ using the AmpliTaq DNA Polymerase (Perkin-Elmer, Norwalk, CT). Automated DNA sequencing (ABI 377; Applied Biosystems, Foster City, CA) confirmed the identity of the amplified bands.

Cell death analysis. PCD was determined by terminal deoxynucleotidyl transferase-mediated biotinylated UTP nick end labeling (TUNEL) using the In Situ-Cell-Death Detection Kit, AP (Boehringer Mannheim, Mannheim, Germany), as suggested by the manufacturer. TUNEL labeling was performed in toto on chick embryos of stages 14-22 and on E9.5-E11 mouse embryos fixed overnight at $4{ }^{\circ} \mathrm{C}$ in $4 \%$ formaldehyde in $0.1 \mathrm{~m}$ phosphate buffer, $\mathrm{pH}$ 7.3. This assay was used also on cryostat and paraffin sections of embryos and on vesicle cultures. Cell death in the vesicle cultures was routinely determined by staining with Nile blue sulfate (NBS; Sigma, St. Louis, MO) (Teillet et al., 1998). Briefly, cultures were washed in Pannett-Compton saline (PC) and incubated in the same solution containing $10 \mu \mathrm{g} / \mathrm{ml} \mathrm{NBS}$ for $30 \mathrm{~min}$ at room temperature. After a $1 \mathrm{hr}$ wash in PC, cultures were photographed under a stereomicroscope (Leica, Nussloch, Germany) and fixed, and the extent of cell death was quantified.

Organotypic and dissociated cell cultures. Optic vesicles from stage 11-12 embryos were surgically removed with the overlying ectoderm (future lens placode) surrounded by as little mesenchyme as possible. Isolated vesicles were stored in culture medium, while a collagen gel support was arranged on the bottom of a $14 \mathrm{~mm}$ well of four-well dishes (Nunc, Roskilde, Denmark). Collagen gel matrix was prepared as described (Lumsden and Davies, 1983), and $20 \mu \mathrm{l}$ of it was spotted on the dish and allowed to gel for $\sim 15 \mathrm{~min}$. Optic vesicles were trapped with their proximal region on the surface of the collagen gel (see Fig. $5 \mathrm{~A}$ ) and cultured in DMEM and Ham's F12 (1:1) supplemented with N2 (DMEM/F12/N2; Life Technologies, Paisley, United Kingdom) and gentamycin $(50 \mathrm{ng} / \mathrm{ml}$; Life Technologies). Tissues were incubated for 48 $\mathrm{hr}$ in $5 \% \mathrm{CO}_{2}$ at $37^{\circ} \mathrm{C}$ in a humidified incubator. Human recombinant BMP4 (rBMP4) (Genetics Institute, Cambridge, MA) and BMP7 (Creative BioMolecules, Boston, MA) were added to the medium at the concentration of 40 and $100 \mathrm{ng} / \mathrm{ml}$, respectively. In some cases, explant cultures were preincubated for $1 \mathrm{hr}$ with either Noggin protein (Xenopus; a gift from Dr. R. Harland) (Lamb et al., 1993) at $50 \mathrm{ng} / \mathrm{ml}$ or the anti-BMP monoclonal antibody 1B12 (Creative BioMolecules). This antibody, which blocks the activity of different BMPs including BMP7 and BMP4 (Vukicevic et al., 1994; Augsburger et al., 1999), was used at the concentration of $10 \mu \mathrm{g} / \mathrm{ml}$ before addition of BMPs. After $48 \mathrm{hr}$, the cultures were stained with NBS, photographed, and fixed in $4 \%$ formaldehyde. When necessary, the cultures were stained with the TUNEL assay and/or embedded in Fibrowax and processed for immunocytochemistry to verify the identity of lens tissue. Dissociated retina cultures were established from HH18-HH19 chick embryos. Dissected retinas were digested in $\mathrm{Ca}^{2+}$ - and $\mathrm{Mg}^{2+}$-free HBSS, containing $3 \mathrm{mg} / \mathrm{ml}$ bovine serum albumin (BSA), and treated with $1 \mathrm{mg} / \mathrm{ml}$ trypsin for $3 \mathrm{~min}$ at $37^{\circ} \mathrm{C}$. Digestion was stopped by adding $2 \mathrm{mg} / \mathrm{ml}$ soybean trypsin inhibitor. Cells were dissociated mechanically, resuspended in culture medium, and plated on glass coverslips coated with polylysine ( $20 \mu \mathrm{g} / \mathrm{ml}$; Sigma) and laminin $(10 \mu \mathrm{g} / \mathrm{ml}$; Life Technologies). Cells were cultured in DMEM/F12/N2 in the presence or absence of BMP4 (40 ng/ml). 5-Bromo-2'-deoxyuridine (BrdU; $50 \mathrm{ng} / \mathrm{ml}$; Boehringer Mannheim) was added $3 \mathrm{hr}$ after cell plating, and the cultures were fixed after 16 additional hours. Cell proliferation was assessed by immunohistochemical localization of incorporated BrdU, as described below.

Preparation of beads. Carrier beads were prepared and used for exogenous application of proteins as described (Merino et al., 1998). Heparin acrylic beads that are $\sim 80 \mu \mathrm{m}$ in diameter (Sigma) were rinsed with PBS and incubated with $5 \mu \mathrm{l}$ of protein solution at room temperature for $1 \mathrm{hr}$ before use. The concentration of rBMP4 was $1 \mu \mathrm{g} / \mathrm{ml}$. Noggin Xenopus and BSA (Sigma) were both used at $1 \mathrm{mg} / \mathrm{ml}$.

Experimental manipulations. The heads of stage 14 host embryos were visualized with an India ink solution in saline injected underneath the embryo. The vitelline membrane was incised, and heparin beads, incubated in either BSA or the selected protein solution, were implanted into the dorsal mesenchyme of the right eye. Embryos were further incubated until they reached stages 17 (13-16 hr) or 21-23 (48 hr). At the appropriate time, the embryos were fixed in $4 \%$ formaldehyde and processed for TUNEL labeling in toto. Embryos were then photographed, dehydrated, embedded in Fibrowax, and sectioned at $12 \mu \mathrm{m}$. Sections were either mounted with Mowiol or processed for immunohistochemistry. In some cases, BrdU ( $50 \mu \mathrm{g} / \mathrm{egg}$ ) was added to each embryo $30 \mathrm{~min}$ before fixation. The embryos were cryoprotected in sucrose and sectioned on a cryostat at $16-18 \mu \mathrm{m}$.

Immunocytochemistry. Antibody to the phosphohistone H3 (1:1000; Upstate Biotechnology, Lake Placid, NY), a mitosis marker, was used to identify dividing cells (Mahadevan et al., 1991). BrdU incorporation was determined using anti-BrdU antibodies obtained from the Developmental Studies Hybridoma Bank and used in 1:4000 dilution from ascitic fluid. To verify the identity of lens tissue versus the neuroepithelium in the optic vesicle cultures, paraffin sections of the explants were incubated with an antiserum against $\delta$-crystallin (1:1500 dilution; a gift from Dr. J. Piatigorsky, National Eye Institute, National Institutes of Health, Bethesda, MD). Secondary antibodies were peroxidase-conjugated antisheep $\operatorname{IgG}$ and biotinylated anti-rabbit $\operatorname{IgG}$ followed by peroxidasecoupled streptavidin (1:1000 dilution; Jackson ImmunoResearch, West Grove, PA). Antigen localization was achieved by incubation with 30 $\mathrm{mg} / \mathrm{ml} \mathrm{DAB}$ and $0.03 \% \mathrm{H}_{2} \mathrm{O}_{2}$ in PBS or by use of the AEC system (Dako, Carpinteria, CA).

\section{RESULTS}

\section{$B m p 4$ and Bmp7 expression in the developing chick eye}

To address the possible role of BMPs during early stages of chick eye development, we analyzed by in situ hybridization the distribution of BMP4 transcripts during the development of the eye primordium. Furthermore, we have compared it with that of $B m p 7$, another member of the BMP family with a strong expression in the eye. A brief and partial description of these expressions has been reported previously (Francis-West et al., 1994; Golden et al., 1999). Bmp4 mRNAs were first localized to the eye region at $\mathrm{HH} 10-\mathrm{HH} 11$. Expression was restricted to the ecto- 


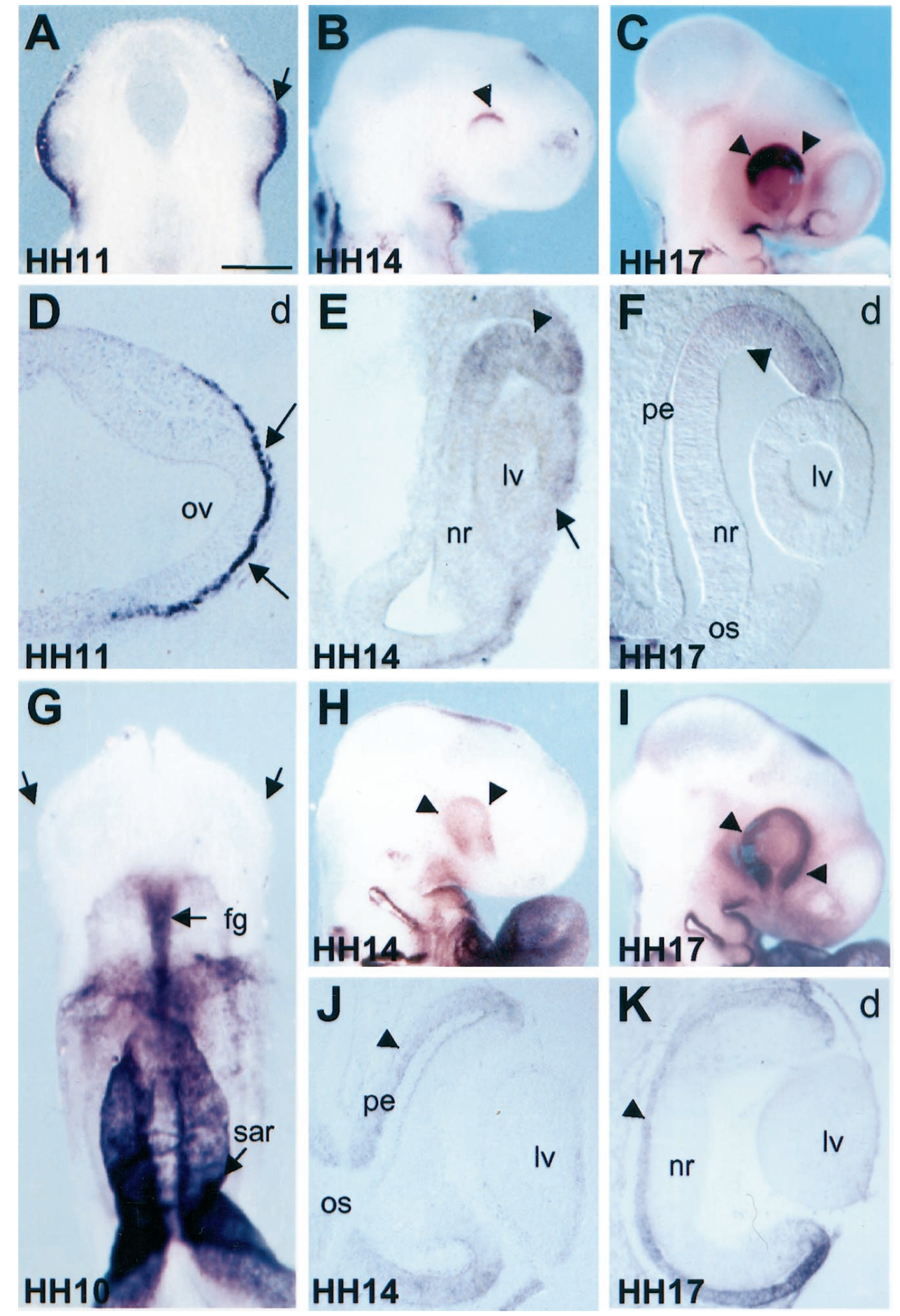

Figure 1. Expression pattern of Bmp4 and Bmp7 in the developing chick optic cup. Embryos of different developmental stages (as indicated in each panel) were hybridized in toto with a digoxigenin-labeled probe against Bmp4 $(A-F)$ and $B m p 7(G-$ $K)$. Embryos are viewed dorsally $(A)$, ventrally $(G)$, or laterally $(B, C, H, I)$. Cryostat $(E, J)$ and paraffin $(D, F, K)$ sections are in the frontal $(E, F, J, K)$ or transversal $(D)$ plane. $A-F$, Note the strong expression of Bmp4 in the region of the newly formed optic vesicle $(A$, arrow), limited only to the ectoderm $(D$, arrows $)$. At the stage of the optic cup, the increasingly strong expression of $B m p 4$ is limited to the dorsal portion (B, $C$, arrowheads), localized to the neural retina $(E, F$, arrowheads). Low levels of expression are present in the lens vesicle $(E$, arrow). $G-K$, Note how $B m p 7$ transcripts were totally absent from the optic vesicles ( $G$, arrows) while strongly expressed in other regions of the embryo. Bmp7 mRNAs were first detected in the eye region at the optic cup stage ( $H$, arrowheads) with progressively higher levels of expression $(I, a r-$ rowheads). Note how transcripts are localized only to the developing pigment epithelium (J, K, arrowheads). $d$, Dorsal; $f g$, foregut region; $l v$, lens vesicle; $n r$, neural retina; os, optic stalk; ov, optic vesicle; $p e$, pigment epithelium; sar, sinoatrial region. Scale bar: $A-C, H, I, 220 \mu \mathrm{m} ; G, 150 \mu \mathrm{m} ; D$, $E, F, J, K, 50 \mu \mathrm{m}$. derm overlaying the optic vesicle, from which the lens placode will originate (Fig. 1A,D). As the optic cup formed, Bmp4 mRNAs were detected in the eye neuroepithelium confined to the prospective dorsal neural retina (Fig. $1 B, E$ ). This expression became stronger and occupied the entire dorsal optic cup between HH17 (Fig. 1C,F) and HH20 (data not shown). In contrast, Bmp4 transcripts decreased in the developing lens vesicle where they were no longer detectable at HH17 (Fig. $1 F$ ). The expression of $B m p 7$ was first observed during optic vesicle invagination in the prospective pigment epithelium (Fig. $1 G, H, J$ ). In the chick eye, this region appeared to be the only site of strong $B m p 7$ expression even at later stages (HH17-HH23) of optic cup development (Fig. $1 I, K)$. Hybridizations with BMP4 or BMP7 sense probes did not give any specific signal (data not shown).

Overall Bmp4 and Bmp7 mRNA distribution in the neural component of the chick optic cup is largely overlapping with the expression pattern reported for the mouse (Dudley and Robertson, 1997). In contrast with mice, however, chick lens placode ectoderm did not express Bmp7 but displayed strong Bmp4 expression, which instead has been detected only at very low levels in mice (Dudley and Robertson, 1997; Furuta and Hogan, 1998; Solloway and Robertson, 1999; Wawersik et al., 1999). This pat- 

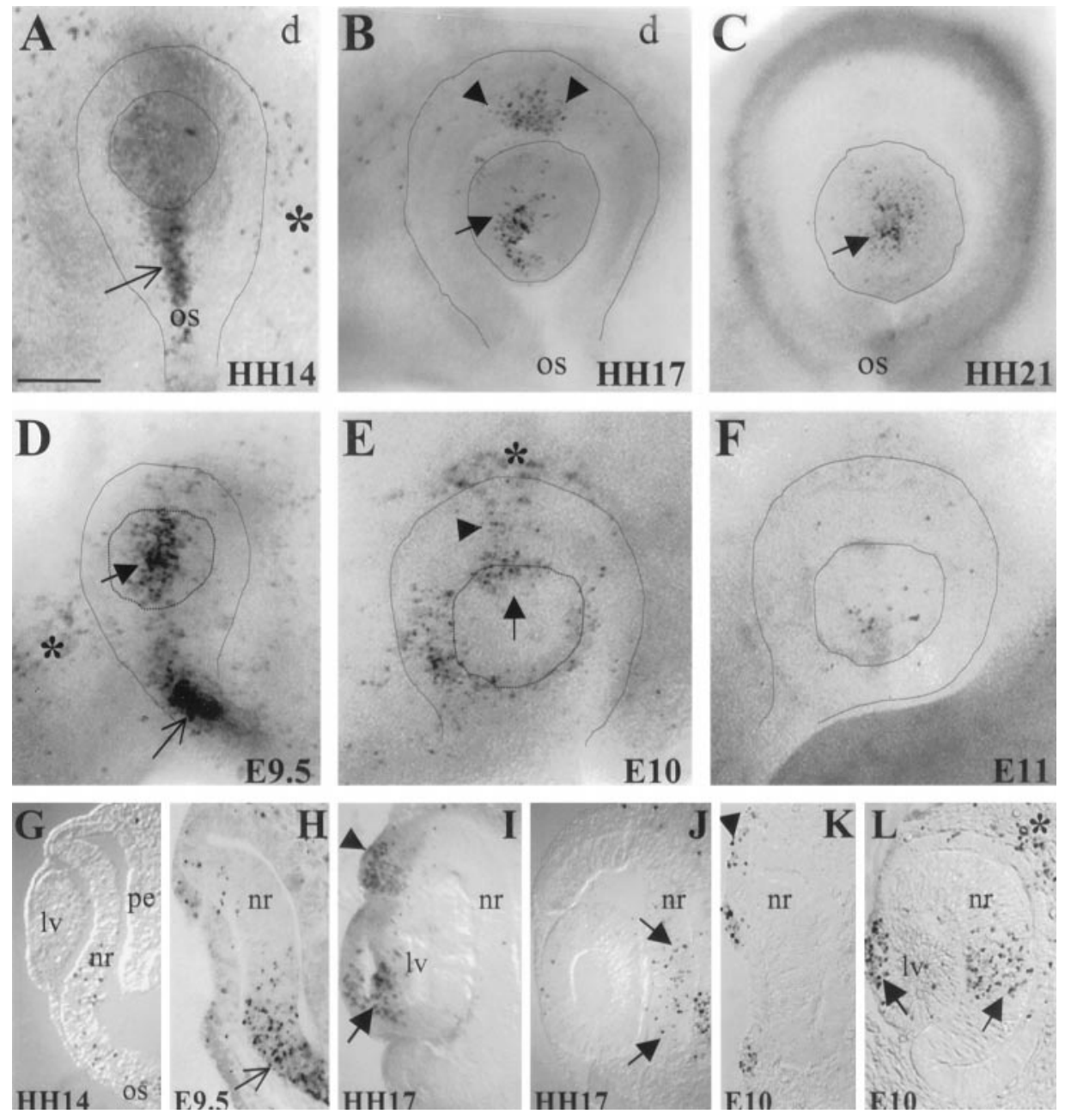

Figure 2. Comparative localization of PCD during chick and mouse optic cup development. Chick embryos of stage HH14 $(A)$, HH17 $(B)$, and HH21 $(C)$ and mouse embryos at E9.5 $(D), \mathrm{E} 10(E)$, and E11 $(F)$ were stained in toto using the TUNEL assay. Frontal cryostat sections of embryos in $A, B, D$, and $E$ are illustrated in $G, I$ and $J, H$, and $K$ and $L$, respectively. The section in $H$ is not meant to illustrate apoptosis in the lens tissue. All images are oriented with dorsal on the top. Observe that in both species there is a similar spatiotemporal distribution of TUNELpositive nuclei in the optic stalk (compare $A, G$ with $D, H$, thin arrows) and in the central region of the retina $(J, L$, thick arrows). Note the extensive and prolonged apoptosis in the murine lens tissue $(D, E, L$, thick arrows) compared with the more limited one in chick $(B, I$, thick arrows). Further note the high concentration of TUNEL-positive nuclei in the dorsal portion of the chick optic cup $(B, I$, arrowheads). Few apoptotic nuclei are observed at the equivalent stage and position in the mouse (E, $K$, arrowheads). Asterisks in $A, D, E$, and $L$ indicate apoptotic nuclei in the mesenchyme surrounding the developing mouse eye. Thick arrow in $C$ points to apoptotic nuclei in the lens vesicle. Dorsal; $l v$, lens vesicle; $n r$, neural retina; os, optic stalk; pe, pigment epithelium. Scale bar: $A, 35 \mu \mathrm{m} ; B, 50 \mu \mathrm{m} ; C, 60 \mu \mathrm{m} ; D, 45$ $\mu \mathrm{m} ; E, K, L, 30 \mu \mathrm{m} ; F, 40 \mu \mathrm{m} ; G, 70 \mu \mathrm{m} ; H, 25$ $\mu \mathrm{m} ; I, J, 80 \mu \mathrm{m}$. tern of expression suggested that BMP4 could be involved in chick retina and lens development.

BMP4 activity in the developing nervous system (NS) has been associated with induction, proliferation, and differentiation as well as PCD (Mehler et al., 1997). However, by the time Bmp4 expression is detectable in the optic cup, the main inductive interactions are completed (Saha et al., 1992), while retina differentiation has not started (Prada et al., 1991). In contrast, Bmp4 expression in the dorsal optic cup could be associated with proliferation or PCD, both occurring at these stages. However, a precise and comparative analysis of PCD in the developing eye was necessary to establish a clear correlation with BMP4 activity. In fact, analysis in amphibians, rodents, and birds did not always coincide, preventing the generalization of the data from one species to the other (Glücksmann, 1951; Silver and Hughes, 1973; Cuadros and Ríos, 1988; Martín-Partido et al., 1988; Laemle et al., 1999).

\section{Comparison of apoptotic cell death in the mouse and chick optic cup}

A detailed distribution of PCD during optic cup formation in chick and mouse was obtained by the whole-mount TUNEL assay, which detects DNA fragmentation characteristic of apoptotic cell death. Analysis was performed on chick embryos of stages comprised between HH14 and HH21 and compared with that of mice at equivalent developmental stages (E9.5-E11). In chick, TUNEL-positive cells were found to be accumulated mainly in four precise and spatiotemporally distinct locations. These are the lens tissue, the ventral stalk region, the prospective central retina, and the dorsalmost part of the optic cup (Fig. 2). Thus, in the stalk region, apoptotic nuclei were visible at $\mathrm{HH} 14$ in the chick (Fig. 2A,G) and at E9.5 in the mouse (Fig. 2D, H). At the same stage, cell death is also prominent in the mouse lens vesicle (Fig. 2D), whereas a similar event was detected only at later stages in the chick (Fig. 2B,I). Cell death in the central portion of the prospective retina was detected in both species after the optic cup invagination. However, apoptotic nuclei were concentrated in a restricted territory in the mouse (Fig. 2L) but were dispersed throughout a large portion of the neuroepithelium in the chick (Fig. $2 J$ ). The remaining region of strong, localized, and transient accumulation of apoptotic nuclei was first detectable in the chick at HH16 in the dorsalmost region of the optic cup with a maximal intensity at HH17 (Fig. 2B). Apoptotic nuclei were dense in the prospective dorsal ciliary margin and in the dorsal prospective neural and pigmented retina (Fig. 2I). TUNEL analysis of mouse embryos at an equivalent stage of optic cup development (E10E10.5) showed accumulation of apoptotic nuclei still in the lens vesicle and in the dorsal aspect of the optic cup (Fig. 2E). However, as shown by tissue sectioning, few apoptotic nuclei were located in the dorsal retina (Fig. $2 K$ ), whereas the majority was associated with the surrounding mesenchyme (Fig. 2L), where Bmp4 is abundantly expressed in the mouse (Dudley and Robertson, 1997). At later stages, few apoptotic nuclei were observed, 

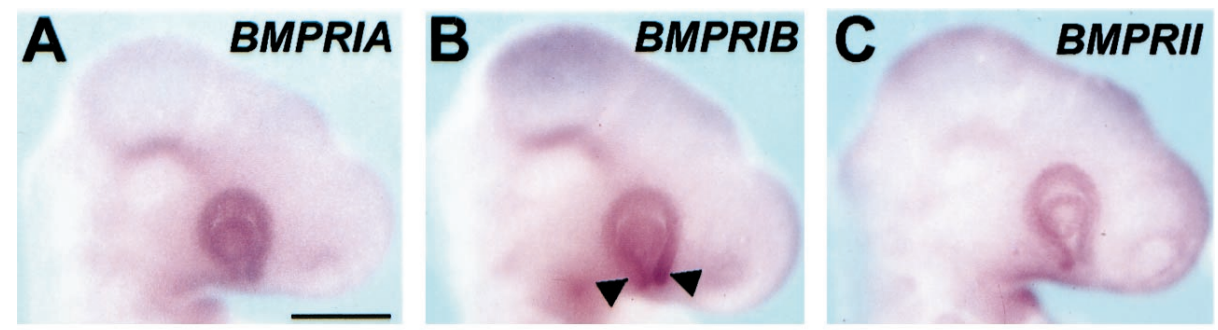

Figure 3. Components of the BMP4 signal transduction pathway are expressed in the optic cup. Lateral views are shown of HH17 $(A-E, G$, $H)$ and $\mathrm{HH} 21(F)$ embryos hybridized in toto with digoxigenin-labeled probes for the chick BmprIA (A), BmprIB (B), BmprII (C), Noggin $(D)$, Smad1 $(E, F), M s x 1(G)$, and Msx2 $(H)$. Note the comparatively higher levels of expression of both Noggin and Smad1 in the dorsal optic cup (D, E, arrowheads) and the extended expression of Smad1 at later stages $(F)$. Note also the higher expression of BmprIB in the optic stalk (arrowheads in $B$ ). The arrow in $D$ indicates expression in the lens vesicle. In the optic cup $M s x 1$ is expressed only dorsally ( $G$, arrowhead), in a region contained within the domain of $M s \times 2$ expression (H, arrowhead). Msx2 transcripts are abundant also in the retro-ocular mesenchyme. Scale bar: $A-H, 345 \mu \mathrm{m}$.
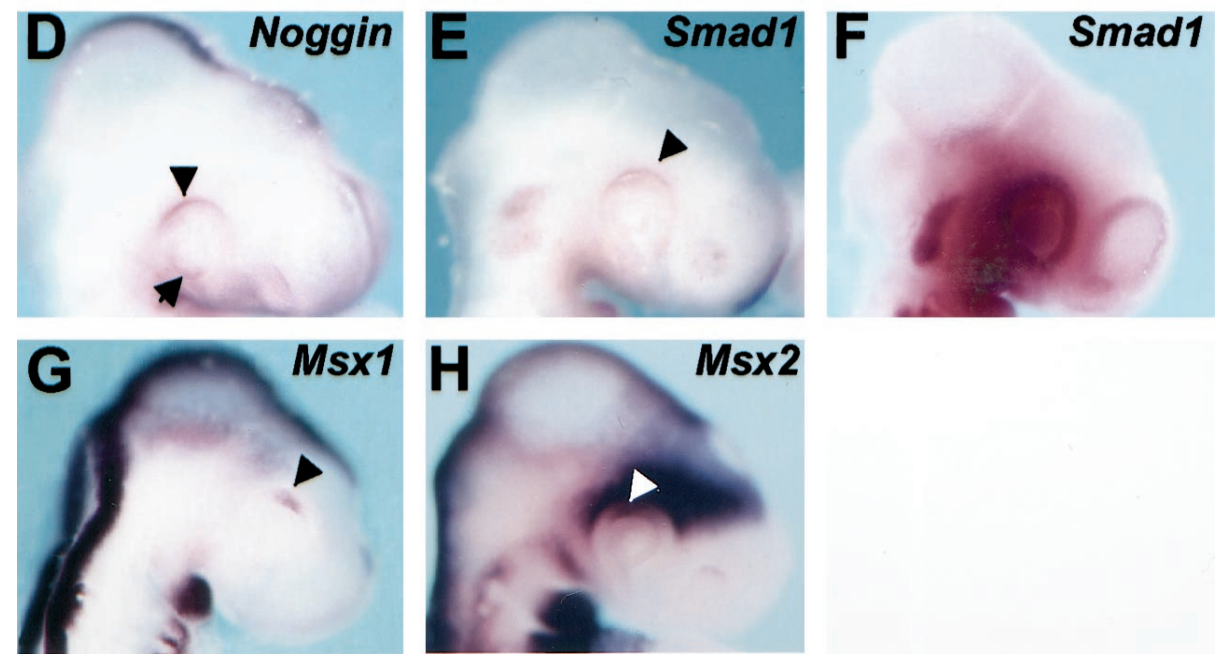

and these were only in the lens tissue (Fig. 2C,F). The coincident spatiotemporal distribution of Bmp4 transcripts and TUNELpositive cells in the dorsal chick optic cup supported a possible local proapoptotic activity.

\section{Components of the BMP signal transduction pathway are expressed in the optic cup}

If BMP4 had a local PCD-inducing activity, then the components of its specific transduction pathway should be expressed also in the same region. BMP signaling requires the heterodimeric interaction of distinct type-I and type-II receptors, both carrying serine-threonine kinase activity (Massagué, 1998). In vitro BMP4 can bind to two different combinations of receptor complexes composed of BMPRII and either BPMRIA or BMPRIB (ten Dijke et al., 1994). This receptor-ligand interaction is modulated by secreted molecules, such as Noggin, Chordin, Follistatin, or Gremlin, which are able to sequester and antagonize BMP4 signaling (Cho and Blitz, 1998; Hsu et al., 1998). Among them, Noggin displays the highest affinity of binding to BMP4 (Zimmerman et al., 1996).

Whole-mount in situ hybridization analysis using sense and antisense probes shows a uniform distribution of BmprIA and $B m p r I I$ transcripts in the entire optic cup (Fig. $3 A, C$ ). BmprIB mRNA displayed an additional stronger localization in the stalk region (Fig. 3B), whereas Noggin was detected in the dorsal aspect of the cup (Fig. 3D). Because the in situ hybridization signals were low, the presence and distribution of these molecules in the optic cup were further confirmed by RT-PCR analysis. Experiments were designed to detect BmprII, BmprIA, BmprIB, and Noggin specifically in the prospective PE, NR, and lens vesicle isolated from HH17 embryos. As shown in Figure 4, BmprIA, BmprII, and Noggin mRNA could be amplified in all three tissues, although at different levels. In particular, Noggin expression was more abundant in the PE where BmprIB transcripts were also uniquely detected.
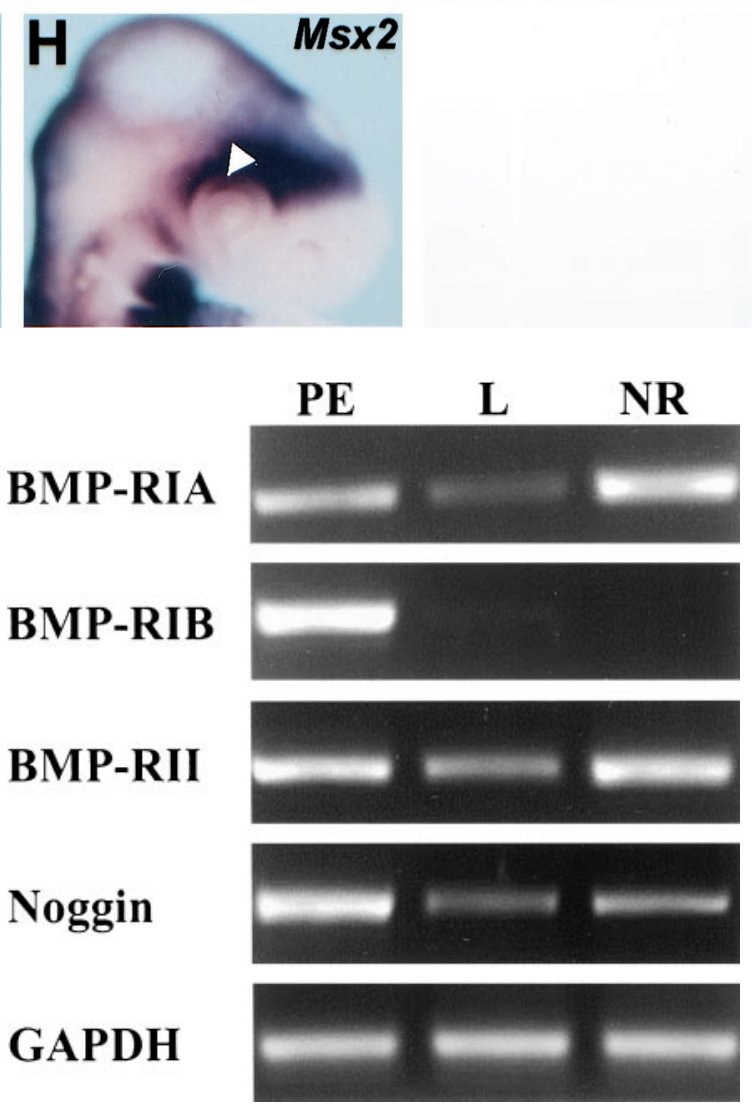

Figure 4. RT-PCR amplifications of BmprIA, BmprIB, BmprII, and Noggin. Amplifications were performed with specific primers on $1 \mu \mathrm{l}$ of cDNA prepared from mRNA from prospective neural retina $(N R)$, pigment epithelium with mesenchyme $(P E)$, and lens $(L)$ of HH17 chick embryos. Amplifications were independently performed three times with similar results. Observe that BmprIA and BmprII mRNAs were amplified from the three components of optic cup analyzed, whereas BmprIB transcripts appeared particularly abundant in the pigment epithelium. Noggin was amplified in the three tissues but with higher levels in the pigment epithelium. $G A D P H$ amplifications are shown for comparison. Identity of the amplified bands was confirmed by automated DNA sequencing.

Downstream propagation of BMP4 signaling is achieved by receptor type-I kinase phosphorylation of SMAD proteins, in particular SMAD1 (Kretzschmar et al., 1997), whereas BMP4mediated PCD appears to be transcriptionally regulated by the activity of the Msx genes, Msx1 and Msx2 (Marazzi et al., 1997; 

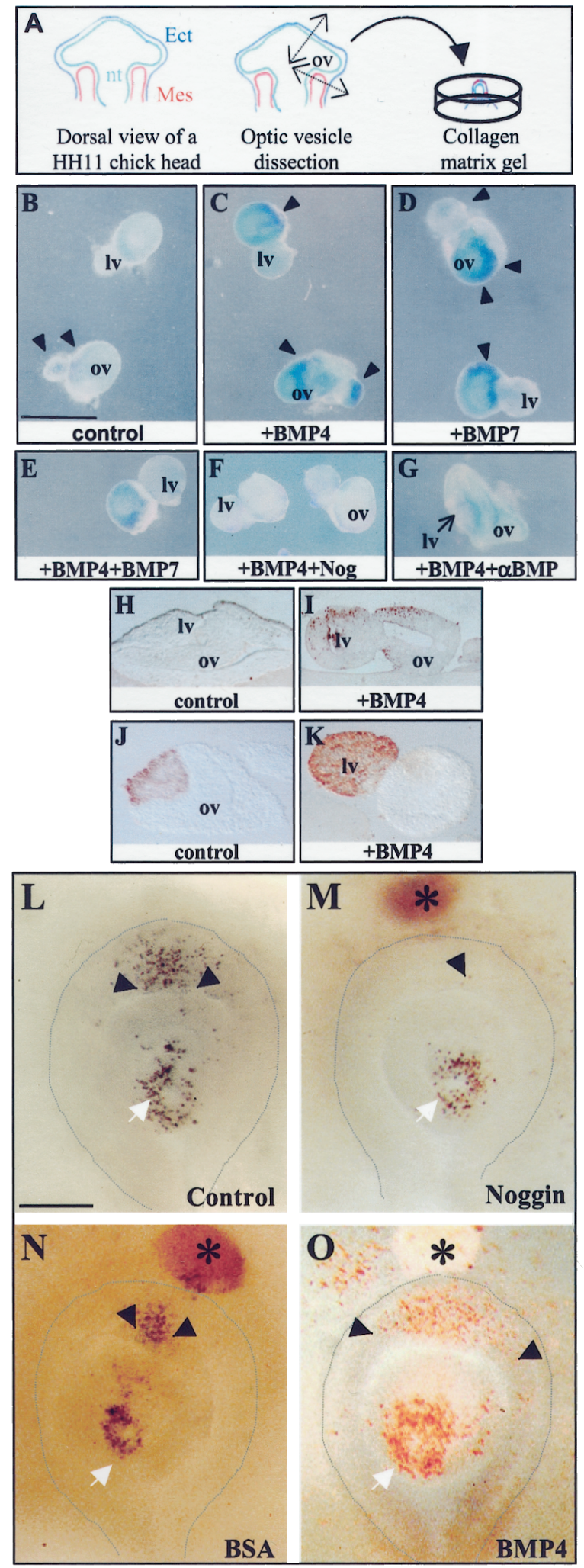

Figure 5. Apoptotic cell death in the developing optic is regulated by BMP4 in vitro and in vivo. $A-K$, The results obtained in experiments in vitro are illustrated. $L-O$, The effects of in ovo exogenous application of noggin and BMP4 are illustrated. $A$, Schematic representation of the design of the optic vesicle culture is shown. The optic vesicles were dissected from stage 11 chick embryos and embedded in collagen gel matrices with the prospective lens placode upward. $B-K$, The vesicles were cultured for $48 \mathrm{hr}$ in the absence (control culture, $B$ ) or presence of BMP4 $(C)$, BMP7 $(D)$, or both $(E)$. In some cases, Noggin $(N o g ; F)$ or
Ferrari et al., 1998). In agreement with the idea that BMP4 signaling is active in the optic cup, expression of Smad1 was limited to the dorsal optic cup, although at low levels in HH17 embryos (Fig. $3 E$ ), whereas it extended to the entire retina at later stages (Fig. $3 F$ ). Similarly, Msxl transcripts were visualized in the dorsal ciliary margin, coinciding with many of the apoptotic nuclei detected at this stage (compare Figs. $3 G$ with $2 B, I$ ). Ms $x 2$ was more widely distributed in the dorsal neural retina and pigment epithelium as well as in the retro-ocular mesenchyme (Fig. $3 H$ ).

\section{BMP4 induces apoptotic cell death and lens growth in organotypic optic vesicle cultures}

Because appropriate components of the BMP4 signal transduction pathway were specifically expressed in the chick optic cup, we developed an optic vesicle organotypic culture to determine whether BMP4 was directly responsible for PCD in the chick optic cup.

The optic vesicle cultures were established as schematically represented in Figure $5 A$. The vesicles were cultured for $48 \mathrm{hr}$ in defined medium with or without BMP4 (40 ng/ml). In controls $(n=64)$, apoptotic nuclei, detected by staining with NBS, were scarce and concentrated in discrete regions (Figs. 5B, 6). Addition of BMP4 increased the density and enlarged the territory of PCD in the majority of the vesicles $(n=69)$ (Figs. 5C, 6). This effect seemed to be prevalent in the neuroepithelium, because apoptotic cell death in the lens tissue was somehow variable and only moderately increased in treated cultures. The activity of BMP4 could be mimicked by the addition of higher concentrations of BMP7 ( $n=22 ; 100 \mathrm{ng} / \mathrm{ml}$ ) (Figs. 5D, 6). To determine whether BMP7 activity was independent from that of BMP4, both cytokines were added together in the cultures. In this condition, however, the amount of apoptotic nuclei appeared to be similar to that observed with each cytokine alone (Fig. $5 E$ ), suggesting that both molecules were competing for the same pathway. The proapoptotic activity of BMP4 could be prevented by the presence of its antagonist Noggin $(50 \mathrm{ng} / \mathrm{ml})$ (Figs. $5 F, 6)$ or by treatment of

BMP-blocking antibody $(\alpha B M P ; G)$ was incubated with the vesicles before the addition of the cytokines. The extent of apoptotic cell death was determined by NBS staining. Both BMP4 and BMP7 increased the amount of blue-stained cells (arrowheads) in the optic vesicles as well as the size of the lens vesicles as compared with control cultures (compare $B$ with $C, D$ ). No synergistic effect was observed when both cytokines were added together $(E)$. Note that both Noggin and anti-BMP7 antibody prevented the apoptotic cell death induced by BMP4 $(F, G)$. TUNEL staining on paraffin sections of the cultured vesicles further confirms the increased cell death induced by BMP4 $(I)$ when compared with control cultures $(H)$. Immunostaining $(K, J)$ with an antiserum against the lens-specific $\delta$-crystallin protein verified the identity of lens tissue. Observe the increased size of the lens tissue in BMP4-treated $(K)$ versus control $(J)$ cultures. $L-O$, Ectopic Noggin represses programmed cell death in the dorsal portion of the chick optic cup. Acrylic-heparin beads containing either Noggin $(M)$, BSA $(N)$, or BMP4 $(O)$ were implanted in the dorsal retro-ocular mesenchyme of HH14 embryos in ovo. The contralateral left eyes were used as the control $(L)$. All images are oriented with dorsal on the top. At HH17, embryos were fixed and stained in toto with TUNEL. Note that Noggin totally abolishes programmed cell death in the dorsal portion of the optic cup ( $L, M$, arrowheads) but not in the lens vesicle ( $L, M$, arrows). In contrast, addition of exogenous BMP4 increased the extent of TUNEL-positive nuclei normally detected in the optic cup (note the position of the arrowheads in $O$ compared with those in $L$ and $N$ ). Beads containing BSA had no effect on the extent or distribution of programmed cell death in the optic cup $(N)$. The bead position is indicated with an asterisk. ect, Ectoderm; $l v$, lens vesicle; mes, mesoderm; $n t$, neural tube; ov, optic vesicle. Scale bar: $B, 245 \mu \mathrm{m} ; C, E$, $230 \mu \mathrm{m} ; D, 310 \mu \mathrm{m} ; F, 160 \mu \mathrm{m} ; G, 130 \mu \mathrm{m} ; H-K, 170 \mu \mathrm{m} ; L-O, 45 \mu \mathrm{m}$. 


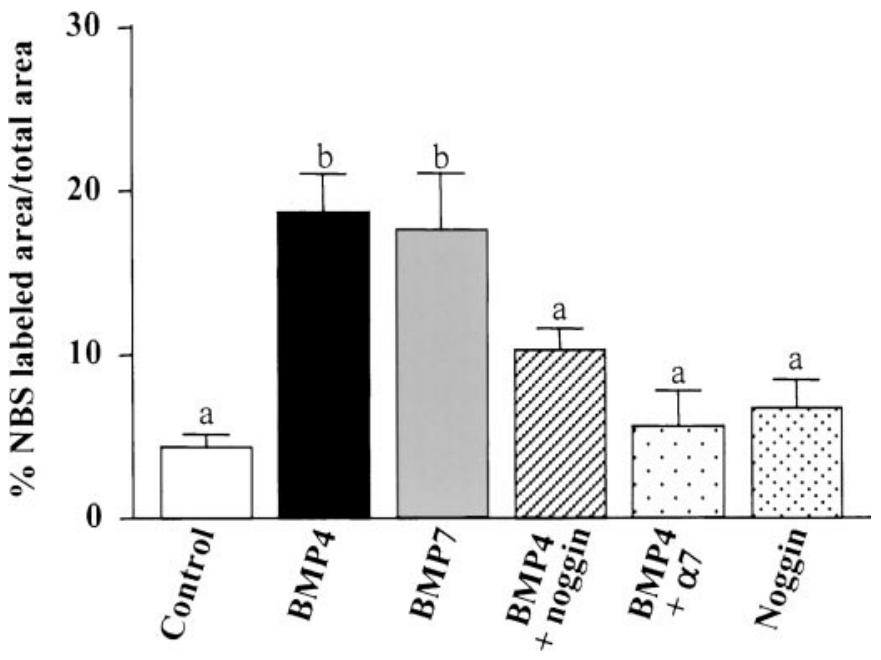

Figure 6. Statistical analysis of apoptotic cell death in control and treated optic vesicle cultures. Intensity of the NBS staining was quantitatively assessed on samples of scanned images representative of each experimental condition. Using an image analysis software (Q500 MC; Leica), the total and stained areas of each vesicle were measured, and the labeling intensity was calculated as the relative surface occupied by the staining. Results are expressed as means $\pm \operatorname{SEM}$. Letters $(a, b)$ have been assigned to groups whose values are significantly different $(a, p<0.05 ; b$, $p<0.001$; Tukey's test). Data were analyzed by one-way ANOVA using the PRISM3 program for IBM. Note how BMP4 $(n=12)$ and BMP7 $(n=13)$ increased the extent of apoptosis in the optic vesicle in comparison with the control ( $n=22 ; p<0.001$, Tukey's test). The effect of BMP4 is significantly reduced in the presence of Noggin $(n=21)$ or of anti-BMP7 antibody ( $\alpha 7 ; n=10 ; p<0.05$ and $p<0.01$, respectively).

the cultures with an antibody that specifically blocks BMP activity (Figs. 5G, 6) (Vukicevic et al., 1994). Apoptosis in the presence of Noggin alone was not significantly different from that of control cultures (Fig. 6). These data were further confirmed with a TUNEL assay on paraffin sections of the cultures. Comparison of Figure 5, $H$ and $I$, clearly shows a larger number of positive nuclei in cultures treated with BMP4.

Although our studies were not specifically aimed at understanding the role of BMPs in lens development, we observed that addition of BMP4 or BMP7 increased the size of the lens vesicle as compared with that in control cultures (Fig. $5 B-D$ ). In general, the ectoderm overlying the vesicles grew to form a lens placode, which expressed $\delta$-crystallin, a lens-specific protein (Fig. 5J,K) (Nickerson and Piatigorsky, 1984). These lens vesicles either developed outside of the optic vesicle $(62 \%$ of the cultures; $n=$ 60) (Fig. $5 B$ ) or were contained within the neuroepithelium that in some cases formed a bilayered optic cup structure (Fig. $5 J$ ). In the presence of either BMP4 or BMP7, the ectoderm overgrew forming large $\delta$-crystallin-positive lens vesicles (Fig. $5 C, D, I, K$ ), which developed in most cases in close proximity to the neural tissue $(57 \% ; n=66)$.

\section{Noggin inhibits programmed cell death in the dorsal optic cup}

To prove further that BMP4 is responsible for PCD in the dorsal optic cup, heparin-acrylic beads containing either Noggin, BMP4, or BSA were implanted in ovo in the retro-ocular mesenchyme of the dorsal right eye of HH14 embryos. The left eye was used as the control. After 13-16 hr of incubation, HH17-HH18 embryos were fixed and processed for the TUNEL assay. When Nogginreleasing beads were used, apoptotic cell death was abolished in the prospective retinal tissue (totally in $45.5 \%$ and partially in
$12.2 \%$ of the treated embryos; $n=33$ ), whereas apoptotic nuclei could still be observed in the majority of the lens tissue $(84.6 \%$ of the embryos; $n=13$ ) (Fig. $5 M$ ). This effect was specific of Noggin because BSA beads did not alter the extent of apoptotic cell death as compared with controls (Figs. $5 L, N$ or $2 B$ ). Furthermore, we determined whether the reinforcement of the endogenous source of BMP4 was able to modify the number of TUNEL-positive cells. Indeed, after implantation of BMP4 beads, the area occupied by apoptotic nuclei extended laterally, embracing a larger portion of the dorsal optic cup in $63.6 \%$ of the embryos $(n=11)$ (Fig. 5O), as compared with controls. This effect was region specific because the implantation of BMP4-soaked beads in the ventral optic cup did not induce ectopic apoptosis in the eye (data not shown), reflecting the dorsal-specific distribution of the BMP signal transduction pathway components.

\section{Noggin reduces cell proliferation in the dorsal optic cup}

The short-term addition of Noggin to the optic cup clearly abolished PCD, but no clear morphological alterations were detectable in the eye as a consequence of this experimental manipulation of BMP4 activity. Thus, we addressed whether the inhibition of BMP4 activity and its consequent suppression of PCD could induce changes in the eye at later stages of development. To this end, the effect of Noggin-bead implantation in the dorsal retroocular mesenchyme of HH14 embryos was evaluated when embryos reached $\mathrm{HH} 23$.

Surprisingly, embryos exposed for longer times to Noggin beads presented eyes with a rounder and symmetric shape (Fig. 7A-D) and with a clear reduction in size $(58.8 \%$ of the embryos; $n=17)$ (Fig. $7 B$ ) as compared with the contralateral eye (Fig. $7 A$ ) or with eyes of embryos implanted with BSA beads $(0 \%$ of the embryos; $n=9$ ) (Fig. 7C,D). Comparison of histological sections of the noggin-treated and control eyes showed a reduction in the thickness of the retina neuroepithelium that was associated with a clear decrease in the amount of cells undergoing mitosis (Fig. 7, compare $F$ with $E, G, H)$. Indeed, the number of $\mathrm{H} 3$-positive cells were significantly reduced in the dorsal portion of Noggin-treated (Fig. $7 F, I)$ as compared with contralateral (Fig. 7E,I) or BSA-treated (Fig. 7G-I) eyes. Assessment of cell proliferation, as determined by BrdU incorporation, gave similar results (data not shown).

The reduced proliferation observed in the presence of Noggin implied that BMP4 could directly induce cell proliferation of retinal cells. To confirm that this was the case, we used dissociated retina cell cultures from $\mathrm{HH} 18$ embryos. As determined by BrdU incorporation, BMP4 induced a statistically significant increase in the number of labeled cells $(14.5 \% ; n=3 ; p<0.0001$, Student's $t$ test) as compared with control cultures.

\section{DISCUSSION}

Several secreted molecules, including BMPs, contribute to the development of the eye in vertebrates. In particular, BMP4 and BMP7 activities are necessary for lens placode induction, and BMP7 is further involved in the proper growth and survival of the retina (Dudley et al., 1995; Luo et al., 1995; Furuta and Hogan, 1998; Wawersik et al., 1999). The data presented here provide evidence that BMP4 has additional roles during eye morphogenesis. In the chick, BMP4, expressed in the dorsal prospective neural retina, is responsible for an apoptotic cell death that occurs with a characteristic spatiotemporal-restricted pattern. Inhibition of BMP4 activity further leads to a clear reduction of the eye size associated with a decrease in the amount 

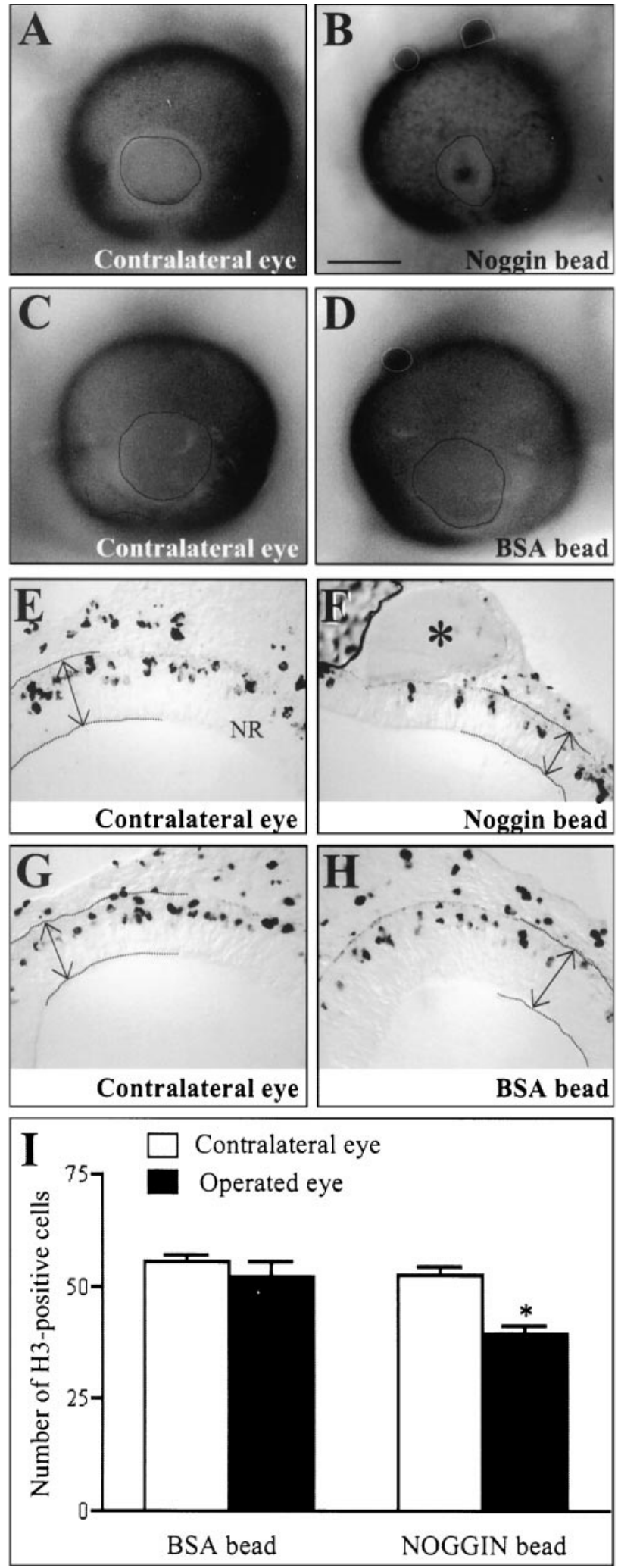

Figure 7. Long-term addition of Noggin reduces eye size and cell proliferation in the dorsal portion of the chick optic cup. Acrylic-heparin beads containing either $\operatorname{Noggin}(B, F)$ or BSA $(D, H)$ were implanted in the dorsal retro-ocular mesenchyme of the right eye of HH14 embryos in ovo. Embryos were analyzed $48 \mathrm{hr}$ after bead implantation (HH23). $A-D$, In toto views of the right, manipulated $(B, D)$ and contralateral, left $(A, C)$ eyes of the treated embryos are shown. $E-H$, Frontal cryostat sections are shown of the eyes depicted in $A-D$, respectively. Sections are immunostained with antibody against phosphohistone H3. Note how a long-term of cells undergoing mitosis in the dorsal optic cup. Therefore, we conclude that BMP4 signaling controls the size of the dorsal optic cup by regulating cell proliferation and apoptosis.

\section{$B m p 4$ and Bmp7 are expressed in separate domains of the developing chick eye}

One of the interesting aspects of our data is the difference in the expression of BMPs between chick and mouse. BMPs are expressed with partially overlapping domains in many regions of the developing vertebrate embryos (Liem et al., 1995; Lyons et al., 1995; Dudley and Robertson, 1997). In particular, Bmp4 and Bmp7 overlap in the prospective lens ectoderm and dorsal neural retina of the mouse embryo (Dudley and Robertson, 1997). In the chick, such overlapping territories cannot be demonstrated, at least by nonradioactive in situ hybridization. Bmp 4 mRNAs are visible in the eye field as soon as the optic vesicles are formed but only in the prospective lens placode ectoderm. In the neuroepithelium, Bmp4 expression starts, in the dorsal half, only after optic vesicle invagination. In contrast, $B m p 7$ was not detected in the eye until HH13, after which its expression is limited to the PE. Therefore, in chick, only Bmp4 is present at the time of lens placode induction, whereas in the neuroepithelium, Bmp4 and Bmp7 localized to different compartments. Additional differences between the chick and mouse distribution of Bmp4 and Bmp7 have been reported in the neural tube and the overlaying ectoderm (Liem et al., 1995; Lyons et al., 1995; Watanabe and Le Douarin, 1996; Dudley and Robertson, 1997; Furuta et al., 1997). In both the eye and the neural tube, interaction between the ectoderm and the neuroepithelium is necessary for proper development of these structures (Spemann, 1938; Liem et al., 1995; Hemmati-Brivanlou and Melton, 1997). Therefore, signaling between these tissues, although leading to the same morphogenetic events, might be mediated by different BMPs in chick and mouse, as suggested previously (Dudley and Robertson, 1997). This exchange of competence will not be difficult to achieve because BMP4 and BMP7 share some of the components of their signaling cascade (Cho and Blitz, 1998; Massagué, 1998). Interestingly, as far as known, BMP receptor distribution appears similar in both species (Dewulf et al., 1995; Zou et al., 1997; Furuta and Hogan, 1998) (this study).

\section{BMP4 is responsible for apoptotic cell death in the chick optic cup}

The life or death of a cell is mostly influenced by extracellular signals, because the intracellular machinery responsible for PCD is constitutively expressed in most animal cells (Chinnaiyan and Dixit, 1996). BMP4 is one of the molecules that trigger PCD of

\section{$\leftarrow$}

exposure to Noggin reduces eye size $(B)$ with respect to contralateral eyes $(A, C)$ or to eyes exposed to BSA $(D)$. Observe that the smaller eye size in Noggin-exposed animals is reflected in a reduction of the neural retina thickness $(F)$ as compared with the contralateral retina $(E)$. This reduction $(E-H$, arrows indicate retina thickness) was never observed in BSAexposed $(H)$ and the corresponding contralateral $(G)$ retinas. The decrease in retina thickness is paralleled by a significant reduction in the number of H3-positive cells (compare staining in $F$ with that in $E, G, H$; asterisk in $F$ marks the Noggin-soaked bead). $I$, Quantification of the number of mitotic cells in treated and control retinas is shown. Values were obtained by counting the number of $\mathrm{H} 3$-positive cells in the entire dorsal portion of the right eye (black bars) of experimental (Noggin; $n=$ 5 ) and control (BSA; $n=5$ ) embryos. Values were compared with those obtained in similar counts of corresponding contralateral eyes (white bars). Note how Noggin-impregnated beads caused a significant reduction (asterisk, $p<0.01$, Tukey's test) in the number of H3-positive cells. Scale bar: $A, 120 \mu \mathrm{m} ; B, 110 \mu \mathrm{m} ; C, D, 130 \mu \mathrm{m} ; E-H, 60 \mu \mathrm{m}$. 
selected mesenchymal cells in different developing structures (Bellusci et al., 1996; Zou and Niswander, 1996; Barlow and FrancisWest, 1997; Jernvall et al., 1998). In the NS such physiological activity has been demonstrated only for neural crest cells of rhombomeres 3 and 5 (Graham et al., 1994) and for cells in the dorsal midline of the anterior forebrain (Furuta et al., 1997). Here, we have provided in vivo evidence that the proapoptotic activity of BMP4 in the NS is extended also to a selected population of neuroepithelial cells in the dorsal optic cup. The implication of BMP4 in this process is confirmed by the strong inhibitory effect of Noggin on apoptosis and by the increase in the number of TUNEL-positive cells in the dorsal retina after exogenous application of BMP4. A local and strictly controlled activity of this cytokine is further supported by the presence in the eye of appropriate BMP receptors and by the restricted and overlapping distribution of one of the BMP-specific SMADs, Smad1, with that of Bmp4 and apoptotic nuclei. Furthermore, the expression of the BMP antagonist Noggin was higher in the PE, where apoptosis was less evident than in the retina. $M s \times 1$, the expression of which coincides with the distribution of Bmp4 transcripts and apoptotic nuclei, might exert additional regulation. In other developing structures, expression of $M s x$ genes has been tightly implicated in the regulatory network of BMP signaling (Graham et al., 1994; Gañan et al., 1996; Barlow and Francis-West, 1997; Ferrari et al., 1998; Yamamoto et al., 2000). In particular, telencephalic explants upregulate their expression of Msx1 and undergo apoptosis in response to BMP4-releasing beads (Furuta et al., 1997). The function of MsxI in the optic cup could be similar, although on the basis of its expression we cannot exclude Msx2 involvement.

In vitro BMP7 mimicked, although at higher concentrations, the proapoptotic activity of BMP4 in the vesicle neuroepithelium. This observation, together with the lack of information on the eye expression of many TGF- $\beta$ family members, raises the possibility that in vivo molecules, other than BMP4, mediate apoptosis in the dorsal optic cup. However, we do not favor this hypothesis. Bmp2, $B m p 5$, and Bmp6 are not expressed in the dorsal optic cup at the stages in which PCD was observed (Francis-West et al., 1994; Furuta et al., 1997; Golden et al., 1999). In the case of BMP7, the combined addition of both cytokines does not produce additive effects. Furthermore, $B m p 7$ is strongly expressed in the PE, where apoptosis is low, and Bmp7-null homozygous mice do not show alterations in the distribution of TUNEL-positive nuclei (Dudley and Robertson, 1997). BMP4 and BMP7 share the ability to bind to the same receptor combination (Massagué, 1998). Therefore, in vitro both BMP4 and BMP7 could separately trigger cell death, but their total activity will be limited by the availability of the receptors, as suggested by our data.

Interestingly, lens vesicle underwent a specific and localized apoptosis concomitantly to that of the dorsal neuroepithelium. Interfering with BMP4 signaling in vivo did not modify lens PCD. In contrast, an overgrowth of $\delta$-crystallin-positive lens tissue was consistently observed in vesicles cultured in the presence of BMPs. We are currently addressing this issue, and it seems that the effect of BMPs on lens tissue might be different from those observed in the eye neuroepithelium.

\section{Significance of programmed cell death during eye morphogenesis}

By midcentury, Glücksmann (1951) had observed that during early stages of amphibian eye morphogenesis a large number of cells die with a spatiotemporal-specific pattern. Since then, few reports have described cell death in the lens placode, the ventral portion of the optic cup, as well as the prospective central retina of rodent and birds (Silver and Hughes, 1973; Schook, 1980a,b; Cuadros and Ríos, 1988; Martín-Partido et al., 1988; Laemle et al., 1999). No cell death was observed in the dorsal portion of the cup in rodents (Silver and Hughes, 1973; Laemle et al., 1999), whereas the presence of necrotic cells was reported in chick (García-Porrero et al., 1984). The data provided in this study confirm and extend these findings. Our comparative analysis demonstrates that cells die of apoptosis with similar but not identical spatiotemporal-restricted patterns in chicks and mice, with the exception of PCD in the dorsal optic cup, which is more abundant in the chick. The role of the local PCD observed in the different regions of the optic cup has not been precisely determined. However, it is generally believed that developmental apoptosis is not a stochastic event but in each case serves a specific function, such as the elimination of vestigial structures or the shaping of an organ (Conlon and Raff, 1999). In addition, PCD can correct cell numbers in structures where cells are generated in excess, as in the NS (Henderson, 1996). The timing and location of apoptosis in the lens vesicle and in the optic stalk well suggest their involvement in the separation of the lens vesicle from the surface ectoderm and in the narrowing of the proximal optic vesicle to form the stalk. This shaping function is more difficult to attribute to the apoptosis in the dorsal portion of the chick cup, because it occurs when vesicle infolding is already completed. This BMP4-mediated PCD may instead be the result of an increased rate of cell division, particularly evident in the dorsal retina at this stage (Romanoff, 1960; Coulombre, 1965). As we show here, BMP4 itself induces cell proliferation in vitro and might exert the same activity in vivo, because long-term addition of Noggin clearly reduced retina cell proliferation in ovo. The relationship between apoptotic and proliferating cells has been demonstrated previously in the developing rat cerebral cortex (Thomaidou et al., 1997). Therefore, we propose that BMP4, increasing the rate of cell proliferation with a consequent timeregulated $\mathrm{PCD}$, might control the asymmetric growth of the chick optic cup, which is larger in its dorsal portion. After asymmetry is established, restricted (dorsal) activity is no longer required, and molecules of the BMP4 signal transduction pathway (Smad1) begin to extend to the remaining retina neuroepithelium. The low level of apoptosis observed in the mouse dorsal optic cup, where an asymmetric growth of the dorsal portion of the eye is not evident as in chick, further supports this idea.

\section{REFERENCES}

Augsburger A, Schuchardt A, Hoskins S, Dodd J, Butler S (1999) BMPs as mediators of roof plate repulsion of commissural neurons. Neuron 24:127-141.

Barlow AJ, Francis-West PH (1997) Ectopic application of recombinant BMP-2 and BMP-4 can change patterning of developing chick facial primordia. Development 124:391-398.

Bellusci S, Henderson R, Winnier G, Oikawa T, Hogan BL (1996) Evidence from normal expression and targeted misexpression that bone morphogenetic protein (Bmp-4) plays a role in mouse embryonic lung morphogenesis. Development 122:1693-1702.

Bovolenta P, Mallamaci A, Puelles L, Boncinelli E (1998) Expression pattern of cSix3, a member of the Six/sine oculis family of transcription factors. Mech Dev 70:201-203.

Chinnaiyan AM, Dixit VM (1996) The cell-death machine. Curr Biol 6:555-562.

Cho KWY, Blitz IL (1998) BMPs, Smads and metalloproteases: extracellular and intracellular modes of negative regulation. Curr Opin Genet Dev 8:443-449.

Conlon I, Raff M (1999) Size control in animal development. Cell 96:235-244.

Coucouvanis E, Martin R (1999) BMP signalling plays a role in visceral endoderm differentiation and cavitation in the early mouse embryo. Development 126:535-546. 
Coulombre AJ (1965) The eye. In: Organogenesis (Dehaan RL, Ursprung H, eds), pp 219-251. New York: Holt, Rinehart, and Winston.

Cuadros MA, Ríos A (1988) Spatial and temporal correlation between early nerve fiber growth and neuroepithelial cell death in the chick embryo retina. Anat Embryol (Berl) 178:543-551.

Dewulf N, Verschueren K, Lonnoy O, Moren A, Grimsby S, Vande Spiegle K, Miyazono K, Huylebroeck D, ten Dijke P (1995) Distinct spatial and temporal expression patterns of two type I receptors for bone morphogenetic proteins during mouse embryogenesis. Endocrinology 136:2652-2663.

Dudley AT, Robertson EJ (1997) Overlapping expression domains of bone morphogenetic protein family members potentially account for limited tissue defects in BMP7 deficient embryos. Dev Dyn 208:349-362.

Dudley AT, Lyons KM, Robertson EJ (1995) A requirement for bone morphogenetic protein-7 during development of the mammalian kidney and eye. Genes Dev 9:2795-2807.

Ferrari D, Lichtler AC, Pan ZZ, Dealy CN, Upholt WB, Kosher RA (1998) Ectopic expression of Msx-2 in posterior limb bud mesoderm impairs limb morphogenesis while inducing BMP-4 expression, inhibiting cell proliferation, and promoting apoptosis. Dev Biol 197:12-24.

Francis PH, Richardson MK, Brickell PM, Tickle C (1994) Bone morphogenetic proteins and a signalling pathway that controls patterning in the developing chick limb. Development 120:209-218.

Francis-West PH, Tatla T, Brickell PM (1994) Expression patterns of the bone morphogenetic protein genes Bmp-4 and Bmp-2 in the developing chick face suggest a role in outgrowth of the primordia. Dev Dyn 201:168-178.

Furuta Y, Hogan BLM (1998) BMP4 is essential for lens induction in the mouse embryos. Genes Dev 12:3764-3775.

Furuta Y, Piston DW, Hogan BL (1997) Bone morphogenetic proteins (BMPs) as regulators of dorsal forebrain development. Development $124: 2203-2212$.

Gañan Y, Macias D, Duterque-Coquillaud M, Ros MA, Hurle JM (1996) The role of TGFs and BMPs as signals controlling the position of the digits and the areas of interdigital cell death in the developing chick limb autopod. Development 122:2349-2357.

García-Porrero JA, Colvee E, Ojeda JL (1984) Cell death in the dorsal part of the chick optic cup. Evidence for a new necrotic area. J Embryol Exp Morphol 80:241-249.

Glücksmann A (1951) Cell deaths in normal vertebrate ontogeny. Biol Rev 26:59-86.

Golden JA, Bracilovic A, McFadden KA, Beesley JS, Rubenstein JL, Grinspan JB (1999) Ectopic bone morphogenetic proteins 5 and 4 in the chicken forebrain lead to cyclopia and holoprosencephaly. Proc Natl Acad Sci USA 96:2439-2444.

Graham A, Francis-West P, Brickell P, Lumsden A (1994) The signalling molecule BMP4 mediates apoptosis in the rhomboencephalic neural crest. Nature 372:684-686.

Hamburger V, Hamilton HL (1951) A series of normal stages in the development of the chick embryo. J Morphol 88:49-92.

Hemmati-Brivanlou A, Melton D (1997) Vertebrate embryonic cells will become nerve cells unless told otherwise. Cell 88:13-17.

Henderson CE (1996) Programmed cell death in the developing nervous system. Neuron 17:579-585.

Hogan BLM (1996) Bone morphogenetic proteins: multifunctional regulators of vertebrate development. Genes Dev 10:1580-1594.

Houston B, Thorp BH, Burt DW (1994) Molecular cloning and expression of BMP7 in the chick epiphysial growth plate. J Mol Endocrinol 13:289-301.

Hsu DR, Economides AN, Wang X, Eimon PM, Harland RM (1998) The Xenopus dorsalising factor Gremlin identifies a novel family of secreted proteins that antagonise BMP activities. Mol Cell 1:673-683.

Jernvall J, Aberg T, Kettunen P, Keranen S, Thesleff I (1998) The life history of an embryonic signalling center: BMP-4 induces p21 and is associated with apoptosis in the mouse tooth enamel knot. Development 125:161-169.

Kawakami Y, Ishikawa T, Shimabara M, Tanda N, Enomoto-Iwamoto M, Iwamoto M, Kuwana T, Ueki A, Noji S, Nohno T (1996) BMP signalling during bone pattern determination in the developing limb. Development 122:3557-3566.

Kretzschmar M, Liu F, Hata A, Doody J, Massagué J (1997) The TGFbeta family mediator Smad1 is phosphorylated directly and activated functionally by the BMP receptor kinase. Genes Dev 11:984-995.

Laemle LK, Puszkarczuk M, Feinberg RN (1999) Apoptosis in early ocular morphogenesis in the mouse. Dev Brain Res 11:129-133.

Lamb TM, Knecht AK, Smith WC, Stachel SE, Economides AN, Stahl N, Yancopolous GD, Harland RM (1993) Neural induction by the secreted polypeptide Noggin. Science 262:713-718.

Liem Jr KF, Tremml G, Roelink H, Jessell TM (1995) Dorsal differentiation of neural plate cells induced by BMP-mediated signals from epidermal ectoderm. Cell 82:969-979.

Lumsden AG, Davies AM (1983) Earliest sensory nerve fibres are guided to peripheral targets by attractants other than nerve growth factor. Nature 306:786-788.

Luo G, Hofmann C, Bronckers ALJ, Sohocki M, Bradley A, Karsenty G
(1995) BMP-7 is an inducer of nephrogenesis and is also required for eye development and skeletal patterning. Genes Dev 9:2808-2820.

Lyons KM, Hogan BL, Robertson EJ (1995) Colocalization of BMP7 and BMP2 RNAs suggests that these factors co-operatively mediate tissue interactions during murine development. Mech Dev 50:71-83.

Macias D, Ganan Y, Sampath T, Piedra ME, Ros MA, Hurle JM (1997) Role of BMP-2 and OP-1 (BMP-7) in programmed cell death and skeletogenesis during chick limb development. Development 124:1109-1179.

Mahadevan LC, Willis AC, Barratt MJ (1991) Rapid histone H3 phosphorylation in response to growth factors, phorbol esters, okadaic acid, and protein synthesis inhibitors. Cell 65:775-783.

Marazzi G, Wang Y, Sassoon D (1997) Msx2 is a transcriptional regulator in the BMP4-mediated programmed cell death pathway. Dev Biol 186:127-138

Martín-Partido G, Rodríguez-Gallardo L, Alvarez IS, Navascués J (1988) Cell death in the ventral region of the neural retina during the early development of the chick embryo eye. Anat Rec 222:272-281.

Massagué J (1998) TGF-beta signal transduction. Annu Rev Biochem 67:753-791.

Mehler MF, Mabie PC, Zhang D, Kessler J (1997) Bone morphogenetic proteins in the nervous system. Trends Neurosci 20:309-317.

Merino R, Ganan Y, Macias D, Economides AN, Sampath KT, Hurle JM (1998) Morphogenesis of digits in the avian limb is controlled by FGFs, TGFbetas, and Noggin through BMP signalling. Dev Biol 200:35-45.

Nickerson JM, Piatigorsky J (1984) Sequence of a complete chicken delta-crystallin cDNA. Proc Natl Acad Sci USA 81:2611-2615.

Prada C, Puga J, Lòpez-Mèndez L, Lòpez R, Ramìrez G (1991) Spatial and temporal patterns of neurogenesis in the chick retina. Eur J Neurosci 3:559-569.

Romanoff AL (1960) The avian embryo: structural and functional development. New York. Macmillan.

Saha MS, Servetnick M, Grainger RM (1992) Vertebrate eye development. Curr Opin Genet Dev 2:582-588.

Schook P (1980a) Morphogenetic movements during the early development of the chick eye. A light microscopic and spatial reconstructive study. Acta Morphol Neerl Scand 18:1-30.

Schook P (1980b) Morphogenetic movements during the early development of the chick eye. An ultrastructural and spatial reconstructive study. B. Invagination of the optic vesicle and fusion of its wall. Acta Morphol Neerl Scand 18:159-180.

Silver J, Hughes AF (1973) The role of cell death during morphogenesis of the mammalian eye. J Morphol 140:159-170.

Solloway MJ, Robertson E (1999) Early embryonic lethality in Bmp5; Bmp7 double mutant mice suggests functional redundancy within the 60A subgroup. Development 126:1753-1768.

Spemann H (1938) Embryonic development and induction. New Haven, CT: Yale UP.

Teillet MA, Watanabe Y, Jeffs P, Duprez D, Lapointe F, Le Douarin NM (1998) Sonic hedgehog is required for survival of both myogenic and chondrogenic somitic lineages. Development 125:2019-2030.

ten Dijke P, Yamashita H, Ichijo H, Franzen P, Laiho M, Miyazono K, Heldin CH (1994) Identification of type I receptors for osteogenic protein-1 and bone morphogenetic protein 4. J Biol Chem 269:16985-16988.

Thomaidou D, Mione MC, Cavanagh JFR, Parnavelas JG (1997) Apoptosis and its relation to the cell cycle in the developing cerebral cortex. J Neurosci 17:1075-1085.

Urist MR, Mikulski A, Lietze A (1979) Solubilized and insolubilized bone morphogenetic proteins. Proc Natl Acad Sci USA 76:1828-1832.

Vukicevic S, Latin V, Chen P, Batorsky R, Reddi AH, Sampath TK (1994) Localisation of osteogenic protein-1 (bone morphogenetic protein-7) during human embryonic development: high affinity binding to basement membranes. Biochem Biophys Res Commun 198:693-700.

Watanabe Y, Le Douarin NM (1996) A role for BMP-4 in the development of subcutaneous cartilage. Mech Dev 57:69-78.

Wawersik S, Purcell P, Rauchman M, Dudley AT, Robertson EJ, Maas R (1999) BMP7 acts in murine lens placode development. Dev Biol 207:176-188

Winnier G, Blessing M, Labosky PA, Hogan BL (1995) Bone morphogenetic protein-4 is required for mesoderm formation and patterning in the mouse. Genes Dev 9:2105-2116.

Wozney JM, Rosen V, Celeste AJ, Mitsock LM, Whitters MJ, Kriz RW, Hewick RM, Wang EA (1988) Novel regulators of bone formation: molecular clones and activities. Science 242:1528-1534.

Yamamoto TS, Takagi C, Ueno N (2000) Requirement of Xmsx-1 in the BMP-triggered ventralization of Xenopus embryos. Mech Dev 91:131-141.

Zimmerman LB, De Jesus-Escobar JM, Harland RM (1996) The Spemann organizer signal Noggin binds and inactivates bone morphogenetic protein 4. Cell 86:599-606.

Zou H, Niswander L (1996) Requirement for BMP signalling in interdigital apoptosis and scale formation. Science 272:738-741.

Zou H, Wieser R, Massagué J, Niswander L (1997) Distinct roles of type I bone morphogenetic protein receptors in the formation and differentiation of cartilage. Genes Dev 11:2191-2203. 